\title{
DAC-Liste der Empfängerländer der öffentlichen Entwicklungshilfe
}

(für Notifikationen ab 2006 betreffend die Beiträge der Jahre 2005, 2006 und 2007)

\section{(2) OpenEdition}

\section{Journals}

Édition électronique

URL : http://journals.openedition.org/sjep/94

DOI : 10.4000/sjep.94

ISSN : 1663-9677

\section{Éditeur}

Institut de hautes études internationales et du développement

Édition imprimée

Date de publication : 1 avril 2008

ISBN : 978-2-940415-02-1

ISSN : 1660-5926

Référence électronique

" DAC-Liste der Empfängerländer der öffentlichen Entwicklungshilfe », Schweizerisches Jahrbuch für Entwicklungspolitik [En ligne], 27-1 | 2008, mis en ligne le 20 novembre 2009, consulté le 07 septembre 2020. URL: http://journals.openedition.org/sjep/94 ; DOI : https://doi.org/10.4000/sjep.94 
DAC-Liste der Empfängerländer der öffentlichen Entwicklungshilfe

(für Notifikationen ab 2006 betreffend die Beiträge der Jahre 2005, 2006 und 2007)

\section{Am wenigsten entwickelte Länder (LDC)}

Afghanistan

Angola

Äquatorialguinea

Kap Verde

Kiribati

Äthiopien

Bangladesch

Benin

Komoren

Salomon-Inseln

Bhutan

Burkina Faso

Burundi

Dschibuti

Eritrea

Gambia

Guinea

Guinea-Bissau

Kongo, Demokratische Republik

Laos

Lesotho

Liberia

Madagaskar

Malawi

Malediven

Mali

Mauretanien

Mosambik

Myanmar

Nepal

Niger

Jemen

Ruanda

Sambia

Samoa

São Tomé und Príncipe

Senegal

Sierra Leone

Somalia

Sudan

Tansania

Timor-Leste

Togo

Tschad

Tuvalu

Uganda

Vanuatu

Zentralafrikanische Republik

\section{Sonstige einkommensschwache Länder (BSP pro Einwohner unter 825 Dollar 2004)}

Elfenbeinküste
Ghana
Indien
Kamerun
Kenia
Kirgistan

\section{Länder mit mittlerem Einkommen (untere Einkommensstufe)} (BSP pro Einwohner 826-3255 Dollar 2004)

Ägypten
Albanien
Algerien
Armenien
Aserbaidschan
Bolivien
Bosnien-Herzegowina
Brasilien
China
Dominikanische Republik
Ecuador
El Salvador
Fidschi
Gebiete unter
palästinensischer Verwaltung
Georgien
Guatemala

Guyana
Honduras
Indonesien
Irak
Iran
Jamaika
Jordanien
Kasachstan
Kolumbien
Kuba
Marokko
Marshall-Inseln
Mazedonien, ehemalige
Jugoslawische Republik
Mikronesien
Montenegro
Namibia

\author{
Pakistan \\ Papua-Neuguinea \\ Simbabwe \\ Tadschikistan \\ Usbekistan \\ Vietnam
}

Niue

Paraguay

Peru

Philippinen

Serbien ${ }^{a}$

Sri Lanka

Surinam

Swasiland

Syrien

Thailand

- Tokelau

Tonga

Tunesien

Turkmenistan

Ukraine

-Wallis und Futuna

Weissrussland

- Gebiete.

a Bis Juni 2006 bildeten Serbien und Montenegro den Staat Serbien-Montenegro. 


\section{Länder mit mittlerem Einkommen (obere Einkommensstufe) \\ (BSP pro Einwohner 3256-10065 Dollar 2004)}

- Anguilla

Antigua und Barbuda

Argentinien

Barbados

Belize

Botswana

Chile

Cook-Inseln

Costa Rica

Dominica

Gabun

Grenada
Kroatien

Libanon

Libyen

Malaysia

Mauritius

Mayotte

Mexiko

- Montserrat

- Nauru

Oman

Palagos-Inseln

Panama
Saudi-Arabien ${ }^{1}$

Seychellen

- St. Helena

St. Kitts und Nevis

St. Lucia

St. Vincent und Grenadinen

Südafrika

Trinidad und Tobago

Türkei

Turks- und Caicos-Inseln

Uruguay

Venezuela

Saudi-Arabien wurde 2004 als Land mit hohem Einkommen eingestuft. Gemäss DAC-Bestimmungen betreffend die Revision der Liste der Empfängerländer öffentlicher Entwicklungshilfe wird Saudi-Arabien im Jahr 2008 nicht mehr zu dieser Liste gehören, wenn es 2005 und 2006 ein Land mit hohem Einkommen bleibt.

Im November 2006 sind die hoch verschuldeten armen Länder (HIPC) folgende: Äthiopien, Benin, Bolivien, Burkina Faso, Burundi, Kamerun, Elfenbeinküste, Eritrea, Gambia, Ghana, Guinea, Guinea-Bissau, Guyana, Haiti, Honduras, Kirgistan, Komoren, Kongo (Republik), Kongo (Demokratische Republik), Liberia, Madagaskar, Malawi, Mali, Mauretanien, Mosambik, Nepal, Nicaragua, Niger, Ruanda, Sambia, São Tomé und Príncipe, Senegal, Sierra Leone, Somalia, Sudan, Tansania, Togo, Tschad, Uganda und Zentralafrikanische Republik. 